\title{
Foreign language attrition
}

Monika S. Schmid ${ }^{1}$ and Teodora Mehotcheva ${ }^{2}$

1University of Groningen, 2

Address for correspondence:

Monika S. Schmid

Engelse Taal en Cultuur

Rijksuniversiteit Groningen

Faculteit der Letteren

Postbus 716

9700 AS Groningen

Nederland

m.s.schmid@ rug.nl

\begin{abstract}
The present contribution discusses recent developments and future directions in the attrition of instructed foreign languages, arguing for a distinction between this type of attrition and attrition involving second languages acquired implicitly in an immersion setting. An overview of the history of research in the field and the most prominent findings is provided, followed by a discussion of theoretical models and methodologically problematic issues. We conclude by outlining some future directions for the field.
\end{abstract}




\section{Introduction}

It is usually taken for granted that a foreign language will be forgotten once it is no longer used or studied, regardless of whether it is a school/university acquired language or a language learned abroad. Empirical findings, however, have so far failed to validate this assumption of the inevitability of language attrition. Some studies suggest individual variation in the susceptibility to foreign language attrition, although it is not yet clear what factors cause or contribute to linguistic resilience.

While interest in the phenomenon of language attrition can be traced back to as far as the $16^{\text {th }}$ century (See Berko-Gleason, 1982), it was not until the 1980s that the decrease of linguistic skills in healthy individuals over time began attracting the attention of modern linguistics. In the early years, different terms were used to refer to the same phenomenon, amongst which language attrition, language loss and language regression. However, with the development of the field it became evident that this variation caused confusion. Consequently, language loss was suggested as a cover/general term for any type of decline in linguistic skills, both at individual or group level, encompassing both language shift, an intergenerational and societal phenomenon usually associated with diglossia situations, and language attrition, an intragenerational and individual phenomenon (de Bot \& Weltens, 1995:151; de Bot, 1996:579; Hansen, 2001:61). With some minor exceptions, language regression is now mainly used to denote decay in the linguistic ability of previously normally developing infants, a symptom usually associated with medical conditions such as autism or degenerative disorders of the brain (Hyltenstam \& Viberg, 1994)

Within the field of language attrition, a further distinction is made between L1 attrition or the attrition of a native language associated with immigrants, as in the studies of de Bot and Clyne (1994), Gürel (2004), Hulsen (2000), Köpke, Schmid, Keijzer and Dostert (2007), Opitz (2004), Seliger and Vago (1991), Schmid (2002), Schmid, Köpke, Keijzer and Weilemar (2004), Yağmur, de Bot and Kurzillus (1999), and L2/foreign language (FL) attrition, the attrition of languages acquired later in life.

Traditionally, no distinction is made between L2 and FL attrition, but we shall argue that there are substantial differences between languages that are learned by instruction through explicit processes, where the learner focusses on the input, on rules etc., and naturalistically acquired L2s (for the distinction between learning and acquiring, see Paradis, 2008). This difference 
can in the first instance be ascribed to the amount of input, exposure to and use of the L2, which differ substantially between instructed and immersed language learning. Secondly, the more implicit acquisition process that can be assumed to take place in immersion learning may result in a different representation of the linguistic structures in memory, which in turn may impact on their susceptibility to attrition/forgetting. Thus, we understand L2 attrition to involve the attrition of a naturalistically acquired second language, for example in returnees who revert to using and relying more on their L1 as in Hansen (1999a, b) and Taura (2008). FL attrition, on the other hand deals with a school/university learned language. Previous research on FL attrition includes works by Cohen (1989), Gardner (1985), Nakuma (1997), Starren (1998), Weltens, van Els and Schils (1989), Weltens and Grendel (1993).

To date there is considerable uncertainty regarding the principles governing the phenomenon of language attrition and the factors involved in it (Köpke \& Schmid, 2011; Schmid, 2011). This is especially true for research on L2/FL attrition (Bardovi-Harlig \& Stringer, 2010) which originally inspired interest in the topic of non-pathological language loss (Köpke \& Schmid, 2004) although more recently the focus of attention has predominantly been on native language attrition. Empirical studies exploring L2/FL attrition remain limited, as does the knowledge and understanding of the phenomenon. In a society which is now predominantly multilingual rather than monolingual (Johnson, 2008) and in which people expend time, money and effort on mastering foreign languages, understanding the principles of L2/FL attrition is becoming ever more important. Furthermore, research on FL attrition can have implications not only directly for FL teaching and learning but also for more theoretical linguistic aspects. These include (among others) the organisation of the linguistic information in the brain, its access, retrieval and processing as well as the functioning of human memory.

It is the aim of this article to provide an overview of the state of the art in L2/FL attrition, examine the factors which have been shown to be relevant to the study or are believed to be of importance, discuss the challenges and constraints that any project on the topic faces and finally outline some direction for future research focusing on the possibilities that new technologies from disciplines such as psycho- and neurolinguistics offer for the study of foreign language teaching (FLAt).

\section{Research on L2/FL attrition}

Interest in language attrition was initially fuelled mainly by its possible relevance to SLA, language teaching programs and policies, and the search ways of transforming knowledge of a 
school/university acquired foreign language, which was perceived/assumed to be rather shortlived, into a more permanent skill. It was hoped that in this way the efforts of language teachers, language learning policy makers as well as language students could be made more worthwhile (Köpke \& Schmid, 2004; Schmid forthc. b).

This originally predominantly practical interest soon changed towards investigations that took a more theoretical and empirical stance (Weltens, de Bot, \& van Els, 1986; Weltens, 1988; Seliger \& Vago, 1991). With the exception of Weltens' study, however, the focus of most work was on the attrition of naturalistically acquired L2s, often in situations where these languages had been mastered at near-native proficiency level (Cohen, 1989; Kuhberg, 1992; Olshtain, 1986, 1989; Taura, 2008; Tomiyama, 1999; Weltens, de Bot, \& van Els, 1986; Yoshitomi, 1999), with instructed FL attrition remaining an under-researched field that could boast far less studies (Bahrick, 1984 a, b; Cohen, 1986; Cole, 1929; Gardner, Lalonde, Moorcroft, \& Evers, 1987; Grendel, 1993; Nagasawa, 1999; Nakuma, 1997; Russel, 1999; Scherer, 1957; Starren, 1998; Weltens, 1988; Weltens \& Grendel, 1993). Furthermore, some of these were small case studies and/or dealt with children (Cohen, 1986; Cole, 1929; Gardner et al., 1987; Nagasawa, 1999; Starren, 1998). In particular the latter investigations can probably not be generalized to larger populations. The question of how much of the (often) laboriously acquired foreign language knowledge is retained later in life, which was posed by Weltens more than twenty years ago (Weltens, 1987: 22) can therefore still be considered wide open.

After a hiatus of close to twenty years, two recent, larger-scale studies address this gap: Mehotcheva's (2010) investigation on the attrition of university acquired Spanish later practiced in real life among Dutch and German university students and Xu's (2010) study on the attrition and retention of school-learned English in Chinese and Dutch university students. Both studies find that the language skills on a range of tasks of the learners they investigated are affected by attrition to some degree, but conclude that attrition is not a linear phenomenon and predicted largely by the degree to which the language had been mastered prior to the onset of the attrition period.

While these studies attempt to lay the groundwork for future research, much remains left to do on the topic. First, there is need to confirm the validity of the existing findings since they are based on a very limited number of studies and target languages. Second, there is still a great deal to be discovered about the governing principles of FL attrition and third, it 
should be further established what factor(s) and/or combination of factors influence the processes of attrition and how.

The main findings in the field so far can be grouped as follows:

- productive skills are more vulnerable to attrition than receptive ones (Hakuta \& D'Andrea, 1992; Weltens, 1988; Weltens \& Grendel, 1993) - the authors did not find signs of attrition in receptive lexical knowledge and concluded that recall is much more challenging than recognition and should be the focus of future studies (see the work by Hansen (2011) on receptive vs. productive lexical knowledge in L2 attrition);

- attrition seems to set in rapidly and then level off (Bahrick, 1984a; Weltens, 1988) - more attrition was found in initial periods (0-3 years) of non-use than in ensuing ones (5-25 years);

- time alone is not enough for a language to attrite (Murtagh, 2003; Weltens, 1988) attrition does not occur only as a function of time of attrition;

- attrition is not a linear process (Mehotcheva, 2010; Taura, 2008) - the length of the incubation period does not predict the amount of loss;

- initial proficiency (Harley, 1993; Mehotcheva, 2010; Murtagh, 2003; Weltens, 1988), course grades and number of courses taken (Bahrick, 1984a) might be predictors of attrition/retention - higher initial proficiency, higher course grades and higher number of courses were associated with better retention of the language;

- once a language is sufficiently established/entrenched, it becomes impervious to deterioration (Bahrick, 1984a, b; Mehotcheva, 2010) (it is unclear to what extent this is linked to proficiency level vs. amount of rehearsal);

- rehearsal during the attrition period is not a sufficient factor to prevent attrition (Bahrick, 1984; Mehotcheva, 2010; Xu, 2010).

It should be noted that generalizing the findings from the earlier FL studies to the present context might be problematic, as foreign language teaching, learning and use have changed considerably over the last two decades. This implies the necessity for FL studies to take into account the characteristics of the language teaching and learning method used at the time of study. As Weltens points out (1988:26), receptive skills were essentially the focus of FL teaching in the 1980 s and little attention was paid to communicative skills and/or the 
ability to talk. Although Weltens refers only to the Dutch school system, it is likely that a similar philosophy obtained elsewhere. Languages used to be taught exclusively in formal settings, there was a very limited input (more often than not only from the teacher) and authentic books, magazines and films in the target language were usually available only at specialized libraries or institutes (e.g. British Council, Cervantes or the Goethe Institut). Speaking and use of the language was also confined to the classroom and opportunities for real-life application were limited to foreign travel (which in itself was less frequent than in the present-day context).

This is quite different from FL learning and use nowadays when languages are not only formally learned at school/university, but many learners avail themselves of the opportunity to get naturalistic input. Languages can even be studied and taught over the Internet without student and teacher sharing the same physical space. Likewise, never before have so many opportunities existed, at least in some parts of the world, to get in direct contact with a foreign language. Globalization, mobility within the EU, the Internet, technological developments and the easy and cheap access to travel have made foreign languages very accessible. Authentic materials like films, music and exercises can be downloaded from the Internet and experienced at the learner's convenience.

These changes have significantly transformed the linguistic profile of populations, especially in Europe where multilingualism is one of the linguistic goals of the Union ${ }^{1}$. EU statistics ${ }^{2}$ show that as of 2006 the majority of the EU population (56\%) spoke at least one foreign language in addition to their mother tongue, $28 \%$ spoke at least two foreign languages and $11 \%$ at least three (note that there was considerable variation across member states, ranging from $99 \%$ of Luxembourgers to only $56 \%$ of Spanish being bi- or multilingual). Considering that there was a $3 \%$ rise in the number of respondents proficient in more than one language since the previous survey carried out in 2001, and that the 2006 data are already outdated, we can assume an even higher multilingual proficiency for the EU population.

In addition to the practical implications ensuing from research on FL attrition which might contribute to better language planning and course syllabus designs and a more effective and efficient language teaching with long lasting results, Van Els and Weltens (1989) and Schmid (forthc. a) argue that there are other important scientific benefits to be gained from attrition

\footnotetext{
${ }^{1}$ http://ec.europa.eu/languages/languages-of-europe/index_en.htm

${ }^{2}$ http://ec.europa.eu/languages/languages-of-europe/eurobarometer-survey_en.htm
} 
research. Among these are contributing to the understanding of human memory and the mechanisms that govern language; better insight into language access and processing, as well as the nature and organization of linguistic knowledge.

\section{Linguistic aspects}

Traditionally language acquisition, whether of L1 or L2, has been regarded as a linear process characterized by a steady upward movement. Language learners, if not affected by some linguistic or cognitive disability, were expected to proceed through analogous stages in acquiring the language, following a very similar rate and pace. Although this might hold true for (monolingual) L1 acquisition, where speakers typically eventually master the language to its full potential, this is not so much the case in L2 or FL acquisition. Research on Second Language Acquisition (SLA) has shown that language learning is not a straightforward process. As de Bot, Lowie and Verspoor (2007) point out, linguistic disciplines such as Cognitive Linguistics and Functional Linguistics, and processing theories such as the Competition model (Bates \& MacWhinney, 1989) have found a multitude of variables to play a role in the language acquisition process. These include factors not only from within the linguistic system but also in the surrounding environment as well as individual characteristics pertaining to each person. The authors also assume that these variables interact on different levels: 'in communication, in constructing meaning, in learning a language and among the languages in the multilingual mind' which makes it difficult to easily predict the final outcome with a simple linear function (de Bot et al.:7).

Dynamic Systems Theory (DST) gradually emerged as a potential candidate to account for language and language development. At the core of DST is the notion of a system as defined by Van Geert:

A system...is more than just a collection of variables or observables we have isolated from the rest of the world. It is a system primarily because the variables mutually interact. That is, each variable affects all the other variables contained in that system and thus also affects itself. This is a property we may call complete connectedness and it is the default property of any system. The principal distinctive property - compared to a constant - is that it changes over time. Consequently, mutual interaction among variables implies that they influence and co-determine each other's changes over time. In this sense, a system is by definition, a dynamic system as a set of variables that mutually affect each other's changes over time.

(1994:50, his emphasis)

Two main characteristics of Dynamic Systems are thus that they are completely connected (all variables are interconnected and if one variables changes, this will affect all the other 
variables in the system) and 'a nesting of larger and larger wholes' (Briggs \& Peat, 1989:148), which means that every system is always a part of another one and that whatever changes occur in one, they will inevitably affect all sub- and super-system(s).

Under the Dynamic Model of Multilingualism (DMM) developed by Herdina and Jessner (2002) language development in a multilingual system is characterized by change of quality, reversibility, stability, complexity, non-linearity and interdependence.

Change of quality refers to the fact that proficiency in a given language may fluctuate - it may deteriorate or improve. This change in quality is a reversible process, i.e. a process of deterioration may be reversed by devoting more time and attention to the language and a process of improvement may slacken and turn into a process of deterioration if a language is neglected. The system may also remain stable as long as the time and effort devoted to maintain its elements remain constant. Accordingly, a multilingual language system is a complex dynamic system which consists of other smaller, nested sub-systems - the different languages spoken by a multilingual. Each sub-system in turn consists of other subsystems such as morphology, syntax, phonology, etc. All these subsystems within the complex system interact between themselves and with the surrounding environment. They are in a process 'of constant adjustment to the changing environment and internal conditions aiming at maintenance of a state of (dynamic) balance' (Herdina \& Jessner, 2002:86).

One aspect of the DMM concerns the positive and negative growth envisioned by the model. Positive growth occurs when time and effort are invested into the language system and it develops. However, if instead of increase of effort there is a decrease in the time devoted to a language, the result is negative growth, which eventually leads to language attrition or gradual language loss. This process is considered to be 'the mirrored process of language acquisition' (Herdina \& Jessner, 2002:91). According to DMM, language attrition very often passes unnoticed, especially in the early stages, because it is demonstrated only by less frequent performance.

Rather than focussing on the process of language attrition itself, DMM considers the language maintenance effort (LME) that bilinguals and multilinguals have to exercise in order to keep their languages 'alive'. According to the authors, LME combines:

1) the use of the language for communication which leads to stimulation of parts of the subsystem, 
2) the verification of hypotheses concerning the language system which again leads to the simulation of some parts of the speaker's linguistic subsystems (2002:99).

If there is no LME due to lack of use of or exposure to a language the model predicts deterioration of competence in that particular language. However, lack of deliberate LME does not necessarily mean that some parts of the language system may not be activated by crosslinguistic influence. Although this might not be enough to fully maintain the system, it might explain why absolute language loss is generally not observed after a certain age/proficiency level.

Even though the authors build up quite a complex model to account for the intricate processes of linguistic growth and decline in multilinguals, there are several weak points that have to be noted. First, although the authors make a special note to the effect that 'language loss will affect different linguistic subsystems to an unequal degree' (Herdina \& Jessner, 2002:97) they do not proceed to develop this idea further. No speculations are offered as to what the differences would be and which one or ones of the subsystems will be more or less affected, i.e. the lexical subsystem, the morpho-syntactic subsystem, the phonological subsystem, etc. Second, nothing is mentioned regarding the order in which the different subsystems will be affected: all systems at the same time but to a different degree, or first one system and then another one, i.e. lexical followed by morphological, and each one to a different degree. Third, and due to the above mentioned problems, the model provides little support for theoretical predictions and expectations, excepting the most general one that multilinguals can be vulnerable to attrition due to the large number of languages that have to be maintained and compete for space in the 'psycho-communicative system' (2002:99).

Another theory that explicitly provides for language attrition is the Neurolinguistic Theory of Bilingualism (NTB) and its Activation Threshold Hypothesis (ATH) developed by Paradis $(1993 ; 2004 ; 2008)$. The theory originated in pathological language loss but has been applied in research on L1 attrition as well (Gürel, 2004; Köpke, 2002; Schmid, 2007; Schmitt, 2010). Its potential with respect to L2 and FL research, however, remains to be explored.

The ATH is based on findings of neuron action potentials, showing that a critical threshold or level of activation must be reached for the cell to generate an action potential (Paradis, 2004:29). Each linguistic item and subsystem has an activation threshold level which depends on the impulses that are necessary to activate it. Activation is achieved 'when a sufficient amount of positive neural impulses have reached its neural substrate' (Paradis, 2004:28). A 
low activation threshold level requires fewer impulses to activate the item, while a higher threshold level requires more. Each activation lowers the threshold which then rises again gradually until the next activation. In order for an item to be selected, activation of the item in question is accompanied by inhibition of its possible competitors, i.e. their activation thresholds are raised (but not beyond a point where they would no more be recognised). Thus, the activation level of any item changes constantly and depends to a great extent on the frequency and recency of use.

Recognition of items is based on stimulation from the outside, such as auditory or visual signals, whereas production of the same item requires an impulse from within the system, thus making it a more difficult process. Accordingly, a person who is not able to produce a word might still be able to recognize and understand it. This is very much in line with findings from FL attrition studies which demonstrate that the receptive skills remain generally intact while production is affected by attrition (Bahrick, 1984a; Hansen, 2011; Weltens, 1989).

An implication of the ATH for bilingual and multilingual speakers is that intensive use of or exposure to a language leads to lowering of the activation threshold of that language thus making it easily available for use. However, all other languages a speaker might know are inhibited. When an item is activated, all its competitors, not only from the same language but also all cross-linguistic translation candidates, are inhibited. Consequently, long-term disuse of a language, accompanied by the use of another, leads to a raising of the level of activation. Access problems may first affect declarative items (lexical words), and later spread to procedural ones (e.g. grammatical rules), leading to a dynamic interference - where the procedures of another language may be used to generate or inform utterances in the attriting one. Under the ATH, lack of use is sufficient for a language to attrite as stated by Paradis (2007:125) '[...], attrition is a result of long-term lack of stimulation'.

The NTB considers language a 'system of systems' (Paradis, 2004:130). The different languages in a bilingual/multilingual are regarded as parametric variations of one and the same thing, i.e. language, and are considered to be subsystems rather than independent systems. Each language subsystem in turn consists of independent subsystems or modules, e.g. phonology, morphosyntax, semantics. This division into modules provides for the possibility of having different levels of activation or inhibition for each separate module, both for the language subsystem as a whole and the modules with it. Thus, while one language subsystem is active, the other language subsystems are inhibited to impede interaction. 
Similarly, the ATH allows for the inhibition of a module within the language subsystem, i.e. morphology, both across all language subsystems and within only one.

The modularity of the language subsystem in the NTB allows for and predicts different attrition rates for the different linguistic components. As morphosyntax and phonology are sustained by procedural memory and vocabulary by declarative memory, it is expected that vocabulary will be affected first. If attrition is to be detected in the early stages of the attrition process, it is going to be in the lexicon, even though Paradis (p.c.) predicts that in FL attrition 'the dominancy of vocabulary over grammar will be less salient to the extent that the grammar is also declarative'. On the other hand, it might be expected that the more mature the language system is at the onset of attrition, the more resistant it would be to attrition. This would predict better retention rates for advanced FL speakers than for speakers at beginner level.

A last important predictor for language attrition from the point of the view of the ATH is motivation, which is thought to play a special part in language retention in the same way that it boosts second language acquisition, in that it may influence the activation threshold level. The emotional attitude towards a language can either raise the activation threshold or lower it (Paradis, 2007). With respect to FL attrition it should be noted that the role of motivation might differ to some extent from L2 or L1 attrition: in natural language acquisition the utterances produced by a speaker usually derive from the genuine need or desire to transmit a message, while in SLA, classroom students are often placed in artificial situations where they have to practice particular and often stereotypical communicative settings, such as asking for directions while looking at a child-like map with the inevitable library, post office and bank pictures. In such situations, the learner's willingness to communicate (WTC) derives more from the syllabus than from within her-/himself and may thus be less susceptible to individual differences than in naturalistic acquisition.

While the ATH bases its predictions for language attrition on the frequency and recency of access of individual items, another very well-known memory-based approach to the phenomenon takes a somewhat different starting point: The Regression Hypothesis (RH), originally formulated by Ribot in the 1880s, which was later used and widely made known by Freud (who coined the term regression) in his work on aphasia. The RH was finally adapted by Jakobson (1968) who applied it to phonological loss in aphasics in comparison to language acquisition in children (Berko-Gleason, 1982, p.17). The RH assumes that the order in which items are forgotten in language attrition is the reverse of the language acquisition process, i.e. 
what is learned last is the first to be forgotten; what is learned first persists the longest. The assumptions underlying these predictions are then linked to the way in which these items are represented in memory, for example the fact that dependency relations involving earlier knowledge often underlie the acquisition of new knowledge. The RH has been applied in several studies on L1 attrition (Håkansson, 1995; Jordens, de Bot, van Os, \& Schumans, 1986; Jordens, de Bot, \& Trapman, 1989; Keijzer, 2008; Schmid, 2002) and on L2 attrition research (Cohen, 1986; Kaufman \& Aronoff, 1991; Hayashi, 1999; Hedgecock, 1991; Kuhberg, 1992; Moorcroft \& Gardner, 1987; Olshtain, 1989; Tomiyama, 1999, 2000).

ATH and RH may be difficult to differentiate in practical terms, since items and features that are learned early are also often the ones that occur with particular frequency. This makes it difficult to determine whether the vulnerability or persistence of a particular item or structure is due to its place in the acquisitional hierarchy or its rehearsal in subsequent use. The matter is further complicated by the fact that other characteristics may further contribute: In his seminal article on the 'linguistic attributes of language attrition' Andersen (1982), suggested that the frequency of items, markedness or functional load and frequency of language usage were all of importance to the process of attrition, determining which part or element of a language would be the first to go. As de Bot and Weltens (1991) argue, these linguistic features are similar to the order in which vocabulary and grammar are presented in FL teaching and learning, i.e. high frequency words are taught and mastered first, followed by gradually less and less frequent items; simple grammatical forms precede more complicated ones. This gave rise to another version of the RH, 'best learned=last forgotten' (Hedgecock, 1991, as cited in de Bot, 1997).

To what extent linguistic items and structures that had once been mastered can actually be 'erased' from memory, as opposed to merely becoming inaccessible in real time, is another controversial notion for attrition research. The Savings Paradigm (Nelson, 1978), is a theory of relearning which has its origins in the widely held psychological view on forgetting assuming that information from memory merely becomes inaccessible due to different factors, but can be retrieved as long as the right cues are used (Loftus \& Loftus, 1976). Support for this has been found in studies using hypnosis to recover an attrited and seemingly totally lost language (Fromm, 1970; Footnick, 2007).

In relation to a forgotten language the savings paradigm is based on the idea that once a word has been learned there are residues of knowledge that can be used to reactivate it. Different 
levels of activation are needed for recall (higher) and recognition (lower), and once the threshold has fallen below the recognition level, the word would usually be considered lost. The Savings Paradigm assumes, however, that the residual knowledge would make it easier to relearn the word than to acquire a new, previously unknown one (de Bot, Martens, \& Stoessel, 2004). Support for the theory has been found in research carried out by de Bot and Stoessel (2000), de Bot, Martens and Stoessel (2004), Hansen (2011), Hansen and Asao (2001), Hansen, Umeda and McKinney (2002), Tomiyama (2001), Yukawa (2001).

The theories and models discussed so far largely depend on the architecture of the linguistic system and underlying models of language acquisition and representation. Language attrition, however, typically also increases the variability observed in the performance among a population. Since most theoretical approaches would assume that this underlying architecture is largely shared among learners who acquired their language - L1, L2 or FL - under similar circumstances, the source for such variation should then be looked for in external (sociolinguistic, biographical, individual) aspects.

\section{Extralinguistic aspects}

Empirical investigations of attrition (L1, L2 or FL attrition) typically show considerable variance within the population, with some speakers/learners attriting to a considerably higher level than others. Different factors have been put forward as promoting better language retention. Within this context, two groups of predictors can be distinguished: personal and external. Among the first ones are age, age at the onset of attrition, attained proficiency and attitude and motivation; among the second time since onset of attrition, language contact and use and/or length of exposure to the language.

Age at onset seems to be of special importance when it comes to language attrition. While studies investigating language attrition in children almost invariably report a considerable decrease in proficiency, sometimes to the degree that the language appears to have been lost entirely (see Nicoladis \& Grabois, 2002; Pallier et al., 2003; Ventureyera \& Pallier, 2004; Ventureyera, Pallier, \& Yoo, 2004), research on adolescent and adult attriters has rarely found any drastic changes in proficiency. It is interesting to note that that the 'cutoff' point (Schmid, 2006:77) coincides with the development of literacy, which has been suggested as a possible explanation for the resistance of language observed after puberty (Hansen, 2001; Köpke, 1999). Age at the onset of attrition has been suggested to be of crucial importance with a 'critical period' for attrition around puberty, i.e. 9-13 years of age (Bylund, 2009; Köpke \& 
Schmid, 2004; Montrul, 2008; Pallier, 2007; Schmid forthc. b). Thus, it appears important to draw a clear distinction between results of studies carried out with children and with adults. Unfortunately, to date there are extremely few investigations which directly compare these two populations.

Attained proficiency at the onset of attrition is especially relevant to research in FL attrition, since otherwise comparable populations of second language learners (same length of exposure, same number of hours of instruction, same age etc.) tend to differ in their proficiency levels in a way that does not apply to the same degree for L1 learners. A higher initial proficiency is often believed to entail better retention of the language. One of the first studies to report a negative correlation between attrition and onset proficiency was GodsallMyers's (1981). However, Bahrick (1984a, 1984b) reports the amount of knowledge that was lost during the first years of attrition to be equal for individuals across different training levels, leaving high proficiency speakers with a higher proportion of knowledge but affecting all populations equally in absolute terms. Bahrick's finding on the extraordinary longevity of a large part of linguistic knowledge, which he referred to as permastore content was also later reinterpreted in terms of a critical threshold of L2 knowledge, since for more proficient learners the information "is tied into an extensive and redundant structure [... that] is sharply resistant to forgetting." (Neisser 1984:34)

Attained proficiency also emerged as a reliable indicator of attrition or retention in a number of other studies: de Bot and Clyne (1989) on the attrition and retention of Dutch and English in Dutch immigrants in Australia; Gardner, Lalonde and MacPherson (1985) on the attrition of school acquired French during the summer vacation; Harley (1993) on the retention of school acquired French by adult Canadians; Mehotcheva (2010) on the attrition retention of Spanish as a FL by Dutch and German university students; Nagasawa (1999) on the attrition and retention of Japanese in graduate students; and Weltens (1988) on the retention of French by Dutch high-school students.

Hansen (1999a) suggested that length of exposure, rather than attained proficiency, was what contributed to higher retention of a language. Again, the two factors are difficult to investigate in isolation: as Schmid (2006:77) noted, it is to be expected that amount of exposure and attained proficiency will correlate in L2 populations, as was found, for example in Study Abroad (SA) research, where longer periods of SA led to higher linguistic gains (Llanes \& Muños, 2009). In Mehotcheva's study (2010) on FL attrition of Spanish in Dutch and German 
ex-Erasmus university students, however, no correlation was found between the time the participants spent in the country speaking the language and the later retention of the language.

Attitude and motivation have emerged as one of the central factors in successful SLA and it has been predicted that 'since attitudinal/motivational characteristics are related to the level of second language proficiency, they will relate to second language retention' (Gardner, 1982:31). However, it has proven difficult to conclusively establish the role of attitudinal factors in attrition. As noted by Dörnyei and Otto (1998) and Schmid (2006) and demonstrated by Nikitina and Furuoka (2005), attitudinal and motivational variables develop dynamically and are subject to change. Although they might truthfully reflect the current attitude and motivation of the participants, these may not be valid for the period when the language was studied and/or used, or for earlier attrition periods. Schmid (2006) also notes that the only studies that have found a correlation between attrition and attitude and motivation are those relying solely on self-evaluation reports to assess language loss as in Moorcroft \& Gardner (1987), Gardner, Lalonde, Moorcroft and Evers (1987) and Waas (1996). Self-evaluation is not always a valid measure for assessing attrition, as participants tend to report greater linguistic loss than objectively found by linguistic tests (Weltens, 1988). More recently, Mehotcheva (2010) investigated the impact of reported attitudes and motivation on actual linguistic proficiency as measured by a range of tasks, but the findings were (yet again) inconclusive. A possible explanation for these results, the author argues, might be problems in the Attitude and Motivational Test Battery - AMBT (Gardner, 1985) used to measure attitude and motivation. Similarly, Schmid and Dusseldorp (2010), who also used the AMTB in a study on the multivariate nature of first language attrition, encountered a perplexing finding (positive attitude towards speakers of the target language was linked to lower lexical diversity), that they could not account for. At the current level of knowledge it cannot be determined whether these conflicting findings are a genuine indication of the absence of a consistent effect of attitude and motivation or the result of methodological shortcomings.

Contact with the language is the one factor that is almost invariably invoked as particularly important in maintaining a language once the speaker has been removed from the environment. It appears logical to assume that the more often a language is used, the better it will be retained and vice versa, as is also predicted by the ATH (Paradis, 2004, 2007; see above). Recency and frequency of use, to use the terms employed by Paradis (2004:28), are 
crucial to maintaining a low activation threshold level and preserving accessibility. Interestingly, however, research on attrition has not found unequivocal support for the importance of rehearsal for the maintenance of an attriting language; whether it is the speaker's L1 (see Schmid, 2007; Schmid \& Dusseldorp, 2010 for a discussion) or L2 (Bahrick, 1984; Mehotcheva, 2010; Xu, 2010).

Again, a problem might lie in the fact that it is difficult to assess the impact of exposure objectively or in isolation from other factors. Language use and contact depend to a certain extent on the speaker and their attitude and motivation (as noted by Köpke \& Schmid, 2004; Schmid \& de Bot, 2006) in the sense that it is up to the individual to seek out opportunities to use the language. Language contact, furthermore, is an extremely diverse factor, encompassing receptive as well as productive activities across a wide range of contexts. How this predictor can be measured and quantified in a manner that is both realistic and valid is still an open question (see Schmid \& Dusseldorp, 2010; Schmid, 2011). This question is especially pertinent since these predictors cannot be observed objectively; they have to be elicited through introspection. In this context, problematic issues concern quantification (e.g. minutes/hours/etc. per day/week/over the last couple of days etc.) as well as the fact that individual perception might vary and be influenced by personal expectations and beliefs.

Another factor which has received very little attention in relation to attrition is the typological proximity between the two contact languages. As de Bot (1997) points out, while the role of cross-linguistic influence in SLA has been extensively researched, its impact on the attrition/retention of a language is much less well understood. For FL attrition, the L1 might have one of two possible roles: facilitatory, where it would be expected that a similarity between the languages would favour retention as in the case of cognates (positive transfer), and inhibitory, where a similarity might cause confusion and the easier blending of the attriting language with the L1, the language of the environment or with a newly acquired language (negative transfer). It is, of course, possible that there may be a different role of typological proximity across different linguistic levels.

Hansen (2011) reports on a study indicating a facilitatory role of language proximity regarding the retention of vocabulary. Hansen and her team compared vocabulary acquisition and attrition of German, Japanese, Korean, Mandarin, Portuguese or Spanish by L1 English missionary learners and found that learners of Spanish and Portuguese retained significantly more words in the target language than learners of the three Asian languages. The author 
points out that the attitude towards the target language and culture of learners of Spanish and Portuguese were found to be significantly more positive than those of learners of the other languages. Similarly, learners of Spanish were especially motivated to maintain their new language upon return to the USA.

\section{Methodological issues and constraints in FL attrition}

Investigations of FL attrition face a number of challenging methodological issues and constraints. These include establishing a baseline and using a suitable methodology to appropriately explore the phenomenon.

The issue of a baseline or reference group has been flagged up as problematic early on in the development of attrition research as a field: As Andersen noted 'we need to know how normal LCs [linguistically competent users] use that feature' (1982:85) in order to be able to say that it has undergone attrition. Even in L1 attrition research, where non-attrited mature monolingual native speakers in the country of origin can easily be found, this issue is by no means straightforward (see Schmid, 2011: ch. 9). Research on FL attrition often deals with languages which have been acquired to different levels of proficiency (research carried out by Murtagh \& Van der Slik, 2004; Reetz-Kurashige, 1999). It is often very difficult (or impossible) to determine ultimate attainment (i.e. level of proficiency before the onset of attrition) for such populations.

The ideal solution to this problem would be to use longitudinal (LG) designs where the same subjects are investigated over different periods of time. This approach would allow establishing a baseline from which the participants start and thus avoid the pitfalls of confusing 'true attrition' with 'failure to acquire', as Andersen (1982:85) put it. There are, however, two serious problems for longitudinal approaches. The first concerns recruitment of a population which not only fits the criteria but will be available for re-testing over years if not decades (recall that Bahrick found linguistic knowledge in the L2 to be fairly stable for 25 years, after an initial attrition period); not to mention the practical difficulties involved with such a long-running project (of which funding is only one). Secondly, each testing session will, in effect, provide the participants with input and training in the attriting language, so that a longitudinal study might even have the effect of preventing the very phenomenon it is looking for.

A possible solution to this problem, as Weltens (1987:27) suggested, would be to use baseline data coming 'from the same - or at least highly comparable - individuals as those whose 
attrition data are used' for whom the process of attrition has not yet set in. This means that the baseline group should consists of individuals who share the characteristics of the experimental or attriting group(s) but who are not (yet) undergoing attrition. In order to minimize the practical problems involved in a longitudinal study, but still be able to investigate true development over time, Mehotcheva (2010) employed a mixed design where participants with varying attrition periods were investigated at two testing moments.

A further problem for attrition studies is the proliferation of testing methods and tasks. Among these are story telling based on a set of pictures (Cohen, 1989; Olshtain, 1989; Taura, 2008; Tomiyama, 1999), recording of spontaneous speech (Tomiyama, 1999; Mehotcheva, 2010), vocabulary recognition and recall (Bahrick, 1984a, 1984b; Mehotcheva, 2010), classical listening and reading tests (Weltens, 1988) and specially designed oral tests (Murtagh, 2003). In a similar fashion, some have focused on language reception (Bahrick, 1984a, 1984b; Weltens, 1988), others on production (Tomiyama, 1999, 2000) or on both (Taura, 2008; Murtagh, 2003).

This lack of a common framework for research design and analysis, in combination with the fact that researchers usually rely on unimodal data, was pointed out by Schmid $(2004 ; 2011)$ as a major drawback in research on attrition. Schmid suggests a combination of formal tasks, free speech and self assessments which would provide the researcher with multimodal data and allow investigating at the phenomenon from different angles. Such a standardization of the methodology would also make the results of different studies comparable and make future replications more meaningful. A number of standardized materials available for Dutch, German and English (both British and American) which have already been used in various studies of L1 attrition (Badstübner, 2011; Cherciov, 2010; Dostert; 2009; Opitz, 2011; Schmid, 2007; Yilmaz, Van der Kooi-Jamjam, \& Schmid, 2009) have recently been made available (www.let.rug.nl/languageattrition).

\section{Conclusions}

The present article has attempted to provide an overview of the research carried out in the field of FL attrition so far and summarize its main findings. It has also pointed out to some major challenges that any project on FL attrition should consider, namely the issue of the reference group and the need for common framework from research design and analysis. Given the multidimensional character and the complexity of the phenomenon, the article proposes a combination of data collection techniques such as formal tasks, free speech data 
and self assessments instead of relying on unimodal data as was typically done in the early studies. In addition, the field should also consider the possibilities that other areas such as psycho- and neurolinguistics offer. Tasks such as Picture Naming, ERPs and Eye-tracking have long been used in SLA studies but so far these have seen very limited use in attrition investigations. To our knowledge, there are only three projects that have employed on-line measures: Dussias (2004) and Dussias and Sagara (2007) who used eye-tracking for the study of Spanish bilinguals; Mehotcheva's (2010) study on the attrition of FL Spanish which employed a Picture Naming task along with other measures. An ongoing project at the University of Groningen furthermore explores the age effect the development of bilingual speakers' L1 and L2, using ERPs and eye-tracking again in combination with other measures. These techniques might provide further understanding of the processing mechanisms employed by attriters, insights into lexical access and retrieval as well as the organization of the multilingual mind in general.

\section{References}

Andersen, R. W. (1982). Determining the Linguistic Attributes of Language Attrition. In R. D. Lambert, \& B. Freed (Eds.), The Loss of Language Skills (pp. 83-118). Rowley, MA: Newbury House.

Badstübner, T. (2011). Ll attrition: German immigrants in the U.S. PhD dissertation, University of Arizona at Tuscon.

Bahrick, B.P. (1984a). Fifty Years of Second Language Attrition: Implications for Programmatic research. The Modern Language Journal, 68(2), 105-118.

Bahrick, B.P. (1984b). Semantic Memory Content in Permastore: Fifty Years of Memory for Spanish Learned in School. Journal of experimental psychology: General, 113(3), 1-29.

Bardovi-Harlig, K., \& Stringer, D. (2010). Variables in Second Language Attrition: Advancing the State of the Art. Studies in Second Language Acquisition, 32(1), 1-45.

Bates, E., \& MacWhinney, B. (1989). Functionalism and the Competition Model. In B. MacWhinney, \& E. Bates (Eds.), The crosslinguistic study of sentence (pp. 3-73). New York: Cambridge University Press.

Berko-Gleason, J. (1982). Insights from Child Language Acquisition for Second Language Loss. In R. D. Lambert, \& B. Freed (Eds.), The Loss of Language Skills (pp. 13-23). Rowley, MA: Newbury House.

Briggs, J., \& Peat D. (1989). Turbulent mirror. An Illustrated Guide to Chaos Theory and the Science of Wholeness. New York: Harper \& Row Publishers.

Bylund, E. (2009). Maturational constraints and First Language Attrition. Language Learning, 59(3), 687-715. 
Cherciov, M. (2010). Between acquisition and attrition: the dynamics between two languages in adult migrants. PdD dissertation, University of Toronto.

Cohen, A. D. (1986). Forgetting Foreign-Language Vocabulary. In B.Weltens, K. de Bot, \& T. van Els (Eds.), Language attrition in progress (pp. 143-158). Dordecht: Foris.

Cohen, A. D. (1989). Attrition in the productive lexicon of two Portuguese third language speakers. Studies in Second Language Acquisition, 11(2), 135-149.

Cole, R. D. (1929). The effect of a summer vacation on students' knowledge of French. Modern Language Journal, 14, 117 - 121.

de Bot, K. (1996). Language loss. In H. Goebl, P.H. Nelde, Z. Starý, \& W. Wölck (Eds.), Kontaktlinguistik. Contact Linguistics. Linguistique de contact (Vol.1, pp. 579-585). Berlin: De Gruyter.

de Bot, K. (1997). Language attrition. In G. R. Tucker, \& D. Corson (Eds.), Encyclopedia of language and education. (Vol. 1, pp. 51 - 62). Dordrecht: Kluwer Academic Publishers.

de Bot, K., \& Clyne, M.G. (1989). Language Reversion Revisited. Studies in Second Language Acquisition, 11, 167-177.

de Bot, K., \& Clyne, M. (1994). A 16-year longitudinal study of language attrition in Dutch Immigrants in Australia. Journal of Multilingual and Multicultrual Development, 15, $17-$ 28.

de Bot, K., Lowie, W., \& Verspoor, M. (2007). A Dynamic Systems Theory approach to second language acquisition. Bilingualism, Language and Cognition, 10(1), 7-21.

de Bot, K., Martens, V., \& Stoessel, S. (2004). The "Savings" approach to testing vocabulary. The International Journal of Bilingualism, 8(3), 373-382.

de Bot, K., \& Stoessel, S. (2000). In Search of Yesterday's words: Reactivating a LongForgotten Language. Applied Linguistics, 21(3), 333-353.

de Bot, K., \& Weltens, B. (1991). Recapitulation, regression and language loss. In H. W. Seliger, \& R. M. Vago (Eds.), First Language Attrition (pp. 31-52). Cambridge: Cambridge University Press.

de Bot, K., \& Weltens, B. (1995). Foreign language attrition. Annual Review of Applied Linguistics, 15, 151-164.

Dörnyei, Z., \& Otto, I. (1998). Motivation in action: A process model of L2 motivation. In: Working Papers in Applied Linguistics (Vol. 4, pp. 43-69). Thames Valley University.

Dostert, S. (2009). Multilingualism, L1 attrition and the concept of 'native speaker'. PhD dissertation, Heinrich-Heine Universität Düsseldorf.

Dussias, P. E. (2004). Parsing a first language like a second: The erosion of L2 parsing strategies in Spanish-English bilinguals. International Journal of Bilingualism 8(3), 355371.

Dussias, P. E., \& N. Sagarra. (2007). The effect of exposure on syntactic parsing in SpanishEnglish bilinguals. Bilingualism: Language and Cognition 10(1), 101-116.

Footnick, R. (2007). A hidden language: Recovery of a 'lost' language is triggered by hypnosis. In B. Köpke, M. S. Schmid, M. Keijzer, \& S. Dostert (Eds.), Language Attrition: Theoretical Perspectives (pp. 169-188). Amsterdam/Philadelphia: John Benjamins. 
Fromm, E. (1970). Age Regression With Unexpected Reappearance of a Repressed Childhood Language. The International Journal of Clinical and Experimental Hypnosis, 18(2), 79-88.

Gardner, R. C. (1982). Social Factors in Language (and Second Language) Retention. In R. D. Lambert, \& B. Freed (Eds.), The Loss of Language Skills (pp. 24-43). Rowley, MA: Newbury House.

Gardner, R. C. (1985). The Attitude Motivation Test Battery Manual. Retrieved February 23, 2008, from University of Western Ontario Website: http://publish.uwo.ca/ gardner/.

Gardner, R. C., Lalonde, R. N., \& MacPherson, J. (1985). Social factors in second language attrition. Language Learning, 3, 519-540.

Gardner, R. C., Lalonde, R. N., Moorcroft, R., \& Evers, F. T. (1987). Second Language Attrition: the role of motivation and use. Journal of Language and Social Psychology, 6(1), 29-47.

Grendel, M. (1993). Verlies en herstel van lexicale kennis [The loss and regaining of lexical knowledge]. Unpublished Ph.D. Dissertation, University of Nijmegen.

Godsall-Myers, J. (1981). The Attrition of Language Skills in German Classroom Bilinguals: A Case Study. Doctoral Dissertation, Bryn Mawr College.

Gürel, A. (2004). Selectivity in L2-induced L1 attrition: a psycholinguistic account. Journal of Neurolinguistics, 17(1), 53-78.

Håkansson, G. (1995). "Syntax and morphology in language attrition: A study of five bilingual expatriate Swedes". International Journal of Applied Linguistics, 13(1), 15371.

Hakuta, K., \& D'Andrea, D. (1992). Some properties of bilingual maintenance and loss in in Mexican background students. Applied Linguistics 13(1), 72-99.

Hansen, L. (1999a). "Not a total loss: The attrition of Japanese negation over three decades". In L. Hansen (Ed.), Second Language Attrition in Japanese Contexts (pp. 142-153). Oxford: Oxford University Press.

Hansen, L. (Ed.). (1999b). Second Language Attrition in Japanese Contexts. Oxford: OUP.

Hansen, L. (2001). Language attrition: The fate of the start. Annual Review of Applied Linguistics, 21, 60-73.

Hansen, L. (2011). The acquisition, attrition, and relearning of mission vocabulary. In M. S. Schmid, \& W. Lowie (Eds.), Modeling Bilingualism: From structure to chaos (pp. 115134). Amsterdam/Philadelphia: John Benjamins.

Hansen, L., \& Asao, T. (2001). Beyond vocabulary: Applying the savings paradigm to the relearning of Japanese grammatical particles. In K. de Bot, \& L. Hansen (Chairs), Reactivating a 'forgotten' language: The savings-paradigm applied. Symposium conducted at AAAL 2001, St. Louis, Missouri.

Hansen, L., Umeda, Y., \& McKinney, M. (2002). Savings in the Relearning of Second Language Vocabulary: The Effects of Time and Proficiency. Language Learning, 52(4), 653-678.

Harley, B. (1993). Maintaining French as a second language in adulthood. Presentation at 10th AILA, Amsterdam. 
Hayashi, B. (1999). "Testing the regression hypothesis: The remains of the Japanese negation system in Micronesia". In L. Hansen (Eds.), Second Language Attrition in Japanese Contexts (pp. 154-168). Oxford: Oxford University Press.

Hedgecock, J. (1991). Foreign language retention and attrition. A study of Regression models. Foreign Language Annals 24, 43-55.

Herdina, P., \& Jessner, U. (2002). A Dynamic Model of Multilingualism: Changing the Psycholinguistic Perspective. Clevedon: Multilingual Matters.

Hulsen, M. E. H. (2000). Language Loss and Language Processing. Three Generations of Dutch Migrants in New Zealand. Unpublished Ph.D. Dissertation, University of Nijmegen.

Hyltenstam, K., \& Viberg, A. (Eds.). (1994). Progression and Regression in Language. Sociocultural, Neuropsychological and Linguistic Perspectives. Cambrige: CUP.

Jakobson, R. (1968). Child Language Aphasia and Phonological Universals. The Hague:

Mouton.

Johnson, K. (2008). An introduction to foreign language learning and teaching. Harlow: Pearson Education Limited.

Jordens, P., de Bot, K., van Os, C., \& Schumans, J. (1986). "Regression in German case marking". In B. Weltens, K. de Bot, \& T. van Els (Eds.), Language Attrition in Progress (pp. 159-174). Dordrecht: Foris.

Jordens, P., de Bot, K., \& Trapmann, H. (1989). Linguistic aspects of regression in German case markings. Studies in Second Language Acquisition, 11(2), 179-204.

Kaufman, D., \& Aronoff, M. (1991). Morphological disintegration and reconstruction in first language attrition. In H. W. Seliger, \& R. M. Vago (Eds.), First Language Attrition (pp. 175-189). Cambridge: Cambridge University Press.

Keijzer, M. C. J. (2008). Language attrition in Dutch emigrants in Anglophone Canada: Internally or externally-induced change? In M. van Koppen, \& B. Botma (Eds.), Linguistics in the Netherlands (pp. 97-108). Amsterdam: John Benjamins.

Köpke, B. (1999). L'atricion de la premier langue chez le bilingue tardif: Implicacions pour l'etude psycholinguisique de bilinguisme. Unpublished $\mathrm{PhD}$ Dissertation, Universite Toulouse-Le Mirail.

Köpke, B. (2002). Activation thresholds and non-pathological L1 attrition. In F. Fabbro (Ed.), Advances in the Neurolinguistics of Bilingualism. Essays in Honour of Michel Paradis. Udine: Forum.

Köpke, B., \& Schmid, M. S. (2004). Language attrition: the next phase. In M. S. Schmid, B. Köpke, M. Keijzer, \& L. Weilemar (Eds.), First Language Attrition: Interdisciplinary perspectives on methodological issues (pp. 1-37). Amsterdam: John Benjamins.

Köpke, B., \& Schmid, M. S. (2011). Aspects psycholinguistiques de l'attrition de la première langue. Accepted for publication in Linguistics, Interaction and Acquisition.

Köpke, B., Schmid, M. S., Keijzer, M., \& Dostert, S. (Eds.). (2007). Language Attrition: Theoretical perspectives. Amsterdam: John Benjamins.

Kuhberg, H. (1992). Longitudinal L2-attrition versus L2-acquisition, in three Turkish children: Empirical findings. Second Language Research, 8, 138-153. 
Llanes, A., \& Muños, C. (2009). A short stay abroad: Does it make a difference? System, 37(3), 353-365.

Loftus, G.R., \& Loftus, E.F. (1976). Human Memory: The Processing of Information. Hillsdale, N.J.: Lawrence Erlbaum Associates.

Mehotcheva, T. H. (2010). After the Fiesta is over: Foreign Language Attrition of Spanish in Dutch and German Erasmus students. PhD Thesis, GRODIL series (86), University of Groningen / RECERCAT, Pompeu Fabra University.

Montrul, S. (2008). Incomplete Acquisition in Bilingualism. Re-examining the Age Factor. Amsterdam: John Benjamins.

Moorcroft, R., \& Gardner, R. C. (1987). Linguistic factors in second language loss. Language Learning, 37(3), 327-340.

Murtagh, L. (2003). Retention and Attrition of Irish as a Second Language. A longitudinal study of general and communicative proficiency in Irish among second level school leavers and the influence of instructional background, language use and attitude/motivation variables. Unpublished Ph.D. Dissertation, Rijksuniversiteit Groningen.

Murtagh, L., \& Van der Slik, F. (2004). Retention of Irish skills: A longitudinal study of a school-acquired second language. International Journal of Bilinngualism, 8(3), 279-302.

Nagasawa, S. (1999). Learning and Losing Japanese as a Second Language: a Multiple Case Study of American University Students. In L. Hansen (Ed.), Second Language Attrition in Japanese Contexts (pp. 169-212). Oxford: Oxford University Press.

Nakuma, C. (1997). A method for measuring the attrition of communicative competence: A pilot study with Spanish L3 subjects. Applied Psycholinguistics, 18, 219-235.

Neisser, U. (1984). Interpreting Harry Bahrick's Discovery: What confers Immunity Against Forgetting? Journal of Experimental Psychology: General, 113(1), 32-35.

Nelson, T. (1978). Detecting small amount of information in memory: Savings for nonrecognised items. Journal of Experimental Psychology: Human Learning and Memory, 4, 453-468.

Nicoladis, E., \& Grabois, H. (2002). Learning English and losing Chinese: A case study of a child adopted from China. The International Journal of Bilingualism, 6(4), 441-454.

Nikitina, L., \& Furuoka, F. (2005). Integrative Motivation in a Foreign Language Classroom: A Study on the Nature of Motivation of the Russian Language Learners in Universiti Malaysia Sabah. Jurnal Kinabalu, Jurnal Perniagaan \& Sains Sosial, 11, pp. 23-34.

Olshtain, E. (1986). The attrition of English as a second language. In B.Weltens, K. de Bot, \& T. van Els (Eds.), Language attrition in progress (pp. 185-202). Dordecht: Foris.

Olshtain, E. (1989). Is Second Language Attrition the Reversal of Second Language Acquisition? Studies in Second Language Acquisition, 11(2), 151-165.

Opitz, C. (2004). Language attrition and language acquisition in a second-language setting. The International Journal of Bilingualism, 8(3), 395-398.

Opitz, C. (2011). A Dynamic Perspective on Late Bilinguals' Linguistic Development in an L2 Environment. Paper presented at the ISB8. 
Pallier, C. (2007). Critical periods in language acquisition and language attrition. In Köpke, M. S. Schmid, M. Keijzer, \& S. Dostert (Eds.), Language Attrition: Theoretical Perspectives (pp.155-168). Amsterdam/Philadelphia: John Benjamins.

Pallier, C., Dehane, S., Poline, J.-B., LeBihan, D., Argenti, A. -M., Dupoux, E., \& Mehler, J. (2003). Brain Imaging of Language Plasticity in Adopted Adults: Can a Second Language Replace the First? Cerebral Cortex, 13, 155-161.

Paradis, M. (1993). Linguistic, psycholinguistic, and neurolinguistics aspects of "interference" in bilingual speakers: The Activation Threshold Hypothesis. International Journal of Psycholinguistics, 9(2), 133-145.

Paradis, M. (2004). A Neurolinguistic Theory of Bilingualism. Amsterdam/Philadelphia: John Benjamins.

Paradis, M. (2007). L1 attrition features predicted by a neurolinguistic theory of bilingualism. In B. Köpke, M. S. Schmid, M. Keijzer, \& S. Dostert (Eds.), Language Attrition: Theoretical Perspectives (pp.121-133). Amsterdam/Philadelphia: John Benjamins.

Paradis, M. (2008). Declarative and Procedural Determinants of Second Languages. Amsterdam/Philadelphia: John Benjamins.

Reetz-Kurashige, A. (1999). Japanese Returnees' Retention of English-Speaking Skills: Changes in Verb Usage over Time. In L. Hansen (Ed.), Second Language Attrition in Japanese Contexts. Oxford: Oxford University Press.

Ribot, T. (1882). Diseases of the Memory: An Essay in the Positive Psychology. New York, NY: D. Appleton and Company. Retrieved November, 2011, from Internet Archive: http://www.archive.org/stream/diseasesofmemory00ribouoft\#page.

Russel, R. A. (1999). Lexical Maintenance and Attrition in Japanese as a Second Language. In L. Hansen (Ed.), Second Language Attrition in Japanese Contexts (pp. 114-141). Oxford: Oxford University Press.

Scherer, G. A. C. (1957). The forgetting rate of learning German. German Quarterly , 30, 275-277.

Schmid, M. S. (2002). First language attrition, use and maintenance: the case of German Jews in anglophone countries. Amsterdam/Philadelphia: John Benjamins.

Schmid, M. S. (2004). A new blueprint for language attrition research. In M. S. Schmid, B. Köpke, M. Keijzer, L. Weilemar (Eds.), First Language Attrition: Interdisciplinary Perspectives on Methodological Issues (pp. 349-363). Amsterdam/Philadelphia: John Benjamins.

Schmid, M. S. (2006). Second Language Attrition. In K. Brown (Ed.), The Encyclopedia of Language and Linguistics, (Vol. 11, pp. 74-81). Amsterdam: Elsevier.

Schmid, M. S. (2007). The role of L1 use for L1 attrition. In B. Köpke, M. S. Schmid, M. Keijzer, \& S. Dostert (Eds.), Language Attrition: Theoretical Perspectives (pp. 135-153). Amsterdam/Philadelphia: John Benjamins.

Schmid, M. S. (2011). Language attrition. Cambridge University Press.

Schmid, M. S. (forthcoming a). Language attrition and multilingualism. In C. A. Chapelle (Ed.), The Encyclopedia of Applied Linguistics. Oxford: Blackwell Wiley. 
Schmid, M. S. (forthcoming b). First language attrition: state of the science and future directions. Accepted for publication in Linguistic Approaches to Bilingualism.

Schmid, M. S., \& de Bot, K. (2006). Language Attrition. In A. Davies, \& C. Elder (Eds.), The Handbook of Applied Linguistics (pp. 210-234). Oxford: Blackwell Publishing.

Schmid, M. S., \& Dusseldorp, E. (2010). Quantitative analyses in a multivariate study of language attrition. Second Language Research, 26(1), 125-160.

Schmid, M. S., Köpke, B., Keijzer, M., \& Weilemar, L. (Eds.), (2004). First Language Attrition: Interdisciplinary perspectives on methodological issues. Amsterdam/ Philadelphia: John Benjamins.

Schmitt, E. (2010). When boundaries are crossed: Evaluating language attrition data from two perspectives. Bilingualism, Language and Cognition, 13(1), 62-72.

Seliger, H. W., \& Vago, R. M. (1991). First Language Attrition. Cambridge: Cambridge University Press.

Starren, M. (1998). Phenomenes de reduction linguistique en situation d'acquisition et d'attrition d'une langue second: A la recherche des elements linguistiques les plus susceptibles de regression. CALAP, 16-17, 51-77.

Taura, H. (2008). Language Attrition and Retention in Japanese Returnee students. Tokyo: Akashi Shoten.

Tomiyama, M. (1999). The First Stage of Second Language Attrition: A Case Study of a Japanese Returnee. In L. Hansen (Ed.), Second Language Attrition in Japanese Contexts (pp. 59-79). Oxford: Oxford University Press.

Tomiyama, M. (2000). Child second language attrition : A Longitudinal Case Study. Applied Linguistics, 21(3), 304-332.

Tomiyama, M. (2001). Detecting a savings effect in longitudinal L2 attrition data. In K. de Bot, \& L. Hansen (Chairs), Reactivating a 'forgotten' language: The savings-paradigm applied. Symposium conducted at AAAL 2001, St. Louis, Missouri.

Van Els, T., \& Weltens, B. (1989). Foreign Language Loss Research from a European Point of View. ITL-Review of Applied Linguistics, 83-84, 19-35.

Van Geert, P. (1994). A dynamic system model of cognitive and language growth. Psychological Review, 98, 3-53.

Ventureyera, V. A. G., \& Pallier, C. (2004). In search of the lost language: The case of adopted Koreans in France. In M. S. Schmid, B. Köpke, M. Keijzer, \& L. Weilemar, (Eds.), First Language Attrition: Interdisciplinary perspectives on methodological issues (pp. 207-224). Amsterdam/ Philadelphia: John Benjamins.

Ventureyera, V. A. ,G., Pallier, C., \& Yoo, H. -Y. (2004). The loss of first language phonetic perception in adopted Koreans. Journal of Neurolinguistics, 17, 79-91.

Waas, M. (1996). Language attrition downunder. Frankfurt: Peter Lang.

Weltens, B. (1987). The Attrition of Foreign-Language Skills: A Literature Review. Applied Linguistics, 8, 22-38.

Weltens, B. (1988). The attrition of French as a foreign language. Dordrecht/Providence: Foris Publications. 
Weltens, B., de Bot, K., \& van Els, T. (Eds.). (1986). Language Attrition in progress. Dordrecht: Foris Publications.

Weltens, B., \& Grendel, M. (1993). Attrition of vocabulary knowledge. In R. Schreuder, \& B. Weltens (Eds.), The bilingual lexicon (pp. 135-157). Amsterdam/Philadelphia: Benjamins.

Weltens, B., Van Els, T., \& Schils, E. (1989). The long-term retention of French by Dutch students. Studies in Second Language Acquisition, 11(2), 205-216.

$\mathrm{Xu}, \mathrm{X}$. (2010). English language attrition and retention in Chinese and Dutch university students. PhD Thesis, GRODIL series (87), University of Groningen.

Yilmaz, G., Van der Kooi-Jamyam, F., \& Schmid, M. S. (2009). Multilingualism and Attrition: Bilingual lexical access in Moroccan Arabic \& Turkish. Paper presented at the 19th EUROSLA conference, Cork.

Yağmur K., de Bot, K., \& Korzilius, H. (1999). Language attrition, language shift and ethnolinguisitc vitality of Turkish in Australia. Journal of Multilingual and Multicultural Development, 20(1), 51-69.

Yoshitomi, A. (1999) On the Loss of English as a Second Language by Japanese Returnee Children. In L. Hansen (Ed.), Second Language Attrition in Japanese Contexts (pp. 80113). Oxford: Oxford University Press.

Yukawa, E. (2001) Attrition, savings, and reactivation of L3 Swedish not used for 5 years. In K. de Bot, \& L. Hansen (Chairs), Reactivating a 'forgotten' language: The savingsparadigm applied. Symposium conducted at AAAL 2001, St. Louis, Missouri. 